\title{
Thanks for the multiple memory systems: Introduction to the special issue in honor of David Sherry
}

\author{
Robert R. Hampton ${ }^{1} \cdot$ Scott MacDougall-Shackleton ${ }^{2}$
}

Accepted: 3 January 2022 / Published online: 1 March 2022

(c) The Psychonomic Society, Inc. 2022

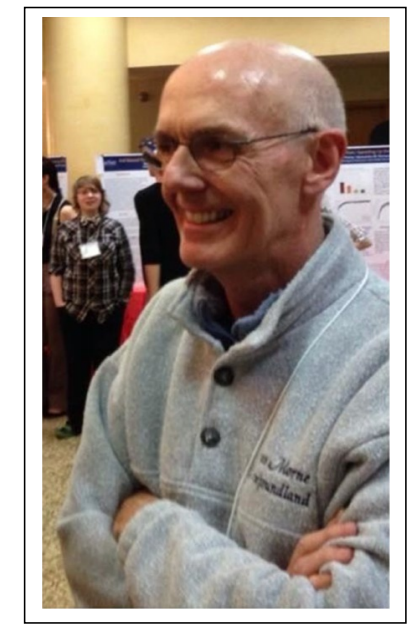

David Sherry,

Comparative Cognition Society Research Award Recipient, 2021 (photo credit Dave Brodbeck).

Editing this special issue of Learning \& Behavior in honor of David Sherry, and preparing a celebration of his career for the 2021 meeting of the Comparative Cognition Society, have left us admiring David more than ever for his positive impact on our field and on the people in it. Finding colleagues who were willing and able to contribute talks and papers in honor of David was easy because he has inspired or trained so many folks in our $\mathrm{CO} 3$ community. Here, we welcome you to the special issue of Learning \& Behavior in honor of David Sherry with a short, and necessarily incomplete, career biography connecting David to the excellent collection of articles in this issue.

Robert R. Hampton

robert.hampton@emory.edu

1 Department of Psychology and Yerkes National Primate Research Center, Emory University, Atlanta, GA 30322, USA

2 Department of Psychology and Advanced Facility for Avian Research, Western University, London, Ontario N6A 5C2, Canada
David began his training as a scientist at a time when "comparative cognition," to the extent that it existed under other names, focused almost entirely on the study of laboratory rats and pigeons. By bringing together ecology, cognition, and neuroscience, he contributed to a revolution in the study of animal psychology, demonstrating the power of approaching cognitive capacities as adaptations that serve natural behavior.

From early days, David's work was characterized by innovative thinking and novel experimentation. David earned his undergraduate degree in psychology at McMaster University, where he did work with Bennett (Jeff) Galef on social learning. This research relationship produced David's first paper, which documented the transmission of food preferences from rat mothers to their pups through the mother's milk (Galef \& Sherry, 1973). More than a decade later, Sherry and Galef surprised students of social learning again with a paper reporting the fact that black-capped chickadees learn faster to open "milk tubs" in the presence of other birds, even though they do not do so by imitating (Sherry $\&$ Galef, 1984, 1990). This work forced a reconsideration about much of what people thought they knew about the cultural transmission of milk-bottle opening by tits in England.

After graduating, David moved a little north and east to Toronto, where he earned his master's and $\mathrm{PhD}$ and worked with Jerry Hogan and Nicholas Mrosovsky on the behavior of jungle fowl. Here, he published on food calls (Sherry, 1977), thermoregulation (Sherry, 1981), and anorexia (Mrosovsky \& Sherry, 1980; Sherry et al., 1980).

David then moved much further east for an NSERCNATO funded postdoc at Oxford University, where he began the work on memory in food-storing birds for which he is so well known. Here, he established an approach that combined thorough knowledge of the ecology of his subjects, field work, and creative and novel experimental techniques. In one example of this creativity, he, Richard Cowie, and John Krebs used a Geiger counter to relocate radioactively labelled seeds they offered birds to cache, allowing them to 
document how marsh tits distribute their cached food and how long they wait to return to collect it (Cowie et al., 1981). In a brilliant experiment that conclusively demonstrated the use of memory to recover cached food, David took advantage of the natural "split brain" of birds. He allowed birds to cache seeds with one eye covered, and then search for the seeds using either the eye that had been functional during caching, or the eye that had been covered. Remarkably, the brain hemisphere receiving input from the functional eye knew the location of cached food even when the other did not (Sherry et al., 1981)!

Returning to Toronto from Oxford, David progressed from postdoc through to associate professor, publishing his classic papers on hippocampal volume and food storing (Sherry et al., 1989), the effects of hippocampal removal on memory for stored food (Sherry \& Vaccarino, 1989), and his landmark paper with Dan Schacter on the evolution of multiple memory systems (Sherry \& Schacter, 1987). This paper is considered by many to have inaugurated a new era in the study of animal cognition, one that combined evolutionary theory, ecology, and neuroscience. If you are new to the field and have not read this last paper, or a more recent update (Sherry, 2006), you are strongly encouraged!

In 1990, David moved to Western University, where he has continued his career since. Over the years, David's research breadth has further grown to include studies of hippocampus and memory in voles (Sherry et al., 1992), cowbirds (e.g., Sherry et al., 1993; Sherry \& Guigueno, 2019), and migratory birds (e.g., Henrique et al., 2021; Magalhaes et al., 2017). He has continued to branch out, training students in more diverse topics to include bee cognition, neurogenesis, and many other topics, always exploiting new technologies and using clever research designs to probe the interface between ecology, animal cognition, and neuroscience. David played a pivotal role in founding the Advanced Facility for Avian Research (http://birds.uwo.ca), and his research programs have helped attract other bird researchers to Western.

David is an outstanding teacher and communicator. Perhaps partly due to his early training in theater, he has a beautiful way of pacing his lectures to achieve a subtle and compelling drama. He is known by former students and colleagues alike for the kind way he teaches, often starting a question with, "I may have misunderstood, but ...," followed by a clear statement of the problem and leading gently to an appropriate answer.

Beyond the classroom, David has been a generous and caring mentor to scores of his own and others' students, and to junior faculty. David has also fostered robust collaborative training partnerships between Canada and Brazil. At Western, he helped develop undergraduate programs in animal behavior and neuroscience, and he was director of an interdisciplinary graduate program in neuroscience. For these and other contributions, he has been recognized with teaching awards, and Western's highest honor, the Distinguished University Professorship.

This special issue, even with so many contributors, fails-as does this brief biography-to capture the breadth of David's research over the years. But it does hint at the diverse contributions he has made both in discovery, situating the comparative study of memory in an evolutionary context, and in training new waves of students interested in understanding the continuities and discontinuities of psychology across species and ecologies. We hope you enjoy the range of work found here.

\section{References}

Cowie, R. J., Krebs, J. R., \& Sherry, D. F. (1981). Food storing by marsh tits. Animal Behaviour, 29, 1252-1259. https://doi.org/10. 1016/s0003-3472(81)80077-2

Galef, B. G., \& Sherry, D. F. (1973). Mothers milk: A medium for transmission of cues reflecting flavor of mothers diet. Journal of Comparative and Physiological Psychology, 83(3), 374-378. https://doi.org/10.1037/h0034665

Henrique, E. P., de Oliveira, M. A., Paulo, D. C., Pereira, P. D. C., Dias, C., de Siqueira, L. S., de Lima, C. M., Miranda, D. D., do Rego, P. S., Araripe, J., de Melo, M. A. D., Diniz, D. G., Magalhaes, N. G. D., Sherry, D. F., Diniz, C. W. P., \& Diniz, C. G. (2021). Contrasting migratory journeys and changes in hippocampal astrocyte morphology in shorebirds. European Journal of Neuroscience, 54(5), 5687-5704. https://doi.org/10.1111/ejn.14781

Magalhaes, N. G. D., Diniz, C. G., Diniz, D. G., Henrique, E. P., Pereira, P. D. C., Moraes, I. A. M., de Melo, M. A. D., Sherry, D. F., \& Diniz, C. W. P. (2017). Hippocampal neurogenesis and volume in migrating and wintering semipalmated sandpipers (Calidris pusilla). PLOS ONE, 12(6), Article e0179134. https:// doi.org/10.1371/journal.pone.0179134

Mrosovsky, N., \& Sherry, D. F. (1980). Animal anorexias. Science, 207(4433), 837-842. https://doi.org/10.1126/science.6928327

Sherry, D. F. (1977). Parental food-calling and role of young in Burmese red junglefowl (Gallus-gallus-spadiceus). Animal Behaviour, 25, 594-601. https://doi.org/10.1016/0003-3472(77)90109-9

Sherry, D. F. (1981). Parental care and the development of thermoregulation in red junglefowl. Behaviour, 76, 250-279. https://doi.org/ 10.1163/156853981x00103

Sherry, D. F. (2006). Neuroecology. Annual Review of Psychology, 57, 167-197. https://doi.org/10.1146/annurev.psych.56.091103. 070324

Sherry, D. F., \& Galef, B. G. (1984). Cultural transmission without imitation: Milk bottle opening by birds. Animal Behaviour, 32, 937-938. https://doi.org/10.1016/s0003-3472(84)80185-2

Sherry, D. F., \& Galef, B. G. (1990). Social-learning without imitation: More about milk bottle opening by birds. Animal Behaviour, 40, 987-989. https://doi.org/10.1016/s0003-3472(05)81004-8

Sherry, D. F., \& Guigueno, M. F. (2019). Cognition and the brain of brood parasitic cowbirds. Integrative Zoology, 14(2), 145-157. https://doi.org/10.1111/1749-4877.12312

Sherry, D. F., \& Schacter, D. L. (1987). The evolution of multiple memory-systems. Psychological Review, 94(4), 439-454. https:// doi.org/10.1037/0033-295X.94.4.439

Sherry, D. F., \& Vaccarino, A. L. (1989). Hippocampus and memory for food caches in black-capped chickadees. Behavioral 
Neuroscience, 103(2), 308-318. https://doi.org/10.1037/07357044.103.2.308

Sherry, D. F., Mrosovsky, N., \& Hogan, J. A. (1980). Weight-loss and anorexia during incubation in birds. Journal of Comparative and Physiological Psychology, 94(1), 89-98. https://doi.org/10.1037/ h0077647

Sherry, D. F., Krebs, J. R., \& Cowie, R. J. (1981). Memory for the location of stored food in marsh tits [Article]. Animal Behaviour, 29, 1260-\&. https://doi.org/10.1016/s0003-3472(81)80078-4

Sherry, D. F., Vaccarino, A. L., Buckenham, K., \& Herz, R. S. (1989). The hippocampal complex of food-storing birds. Brain, Behavior and Evolution, 34(5), 308-317.
Sherry, D. F., Jacobs, L. F., \& Gaulin, S. J. C. (1992). Spatial memory and adaptive specialization of the hippocampus. Trends in Neurosciences, 15(8), 298-303. https://doi.org/10.1016/0166-2236(92) 90080-r

Sherry, D. F., Forbes, M. R. L., Khurgel, M., \& Ivy, G. O. (1993). Females have a larger hippocampus than males in the broodparasitic brown-headed cowbird. Proceedings of the National Academy of Sciences of the United States of America, 90(16), 7839-7843. https://doi.org/10.1073/pnas.90.16.7839

Publisher's note Springer Nature remains neutral with regard to jurisdictional claims in published maps and institutional affiliations. 